\title{
Modified Hot Well Level Control System using Basic Logic Gates
}

\author{
S. Chandrakanth Sagar \\ B.Tech Student \\ JPNCE, Mahabubnagar-509001
}

\author{
M. Narayana, Ph.D \\ HOD-ECE \\ JPNCE, Mahabubnagar-509001
}

\author{
M. Lohitha \\ B.Tech Student \\ JPNCE, Mahabubnagar-509001
}

\begin{abstract}
This paper, proposes simple, low cost, low power consumption, modified hot well level control system using basic logic gates. The control of water level in the hot well is a critical operational consideration. Now a days, modern control techniques using logic gates have been implemented for a lot of industrial models practically. Hence in this paper, it is described about effectiveness of basic logic gates in order to provide better hot well level control. This control system is used to control water level in the hot well to a normal level $200 \mathrm{~mm}$ and to increase the water temperature at the range of $2^{\circ} \mathrm{C}$ to $3^{\circ} \mathrm{C}$.
\end{abstract}

\section{General Terms}

Theory, Performance, Design, Experimentation, Verification, Comparison

\section{Keywords}

PI controller, Basic logic gates, driver IC.

\section{INTRODUCTION}

A power plant requires continuous monitoring inspection at frequence intervals. This can be achieved only by using automated machines. Hence power plant requires automated machines to operate some of the major parts of it [5].

One of the most essential parts in the power plants is hot well. It is also known as condenser. In order to protect low pressure turbine blades from damage, the water level in the hot well is to be maintained at normal level. The existing hot well level control system uses PI controller to maintain hot well level by operating the control valves and where as the proposed control system uses basic logic gates and driver IC's to perform the similar operation as the existing system with including some extra features. The proposed circuit is used to maintain the water level in the hot well to normal level by operating the makeup, drain and emergency pumps based on the level of water. It consists of led's to indicate corresponding water levels in the hot well and consists of a buzzer that gives siren when emergency pump gets on. It also consists of a special led which indicates the safe mode that means when the water level reaches normal i.e., $200 \mathrm{~mm}$, and then it glows. The advantage of this circuit is that it can raise the temperature of water to certain amount that is from $2^{\circ} \mathrm{C}$ to $3^{\circ} \mathrm{C}$.

\section{POWER PLANT PRINCIPLE}

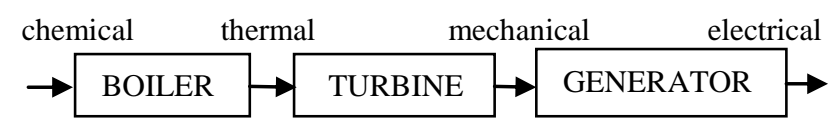

Fig 1. Thermal power plant principle

In the boiler, the chemical energy is converted in to the thermal energy by heating water and converting it in to the steam with the help of the coal. The steam produced in the boiler expands in the turbine. In the turbine the thermal energy of the steam is converted into the kinetic energy which in turn rotates the turbine blades in turn turbine shaft gets rotate. This motion of the turbine shaft makes the rotor of the generator to rotate. This rotor cuts the EMF, which is generated by the stator. Then, the current is induced in the rotor and this is transmitted to various load centers through the transmission lines [2].

\section{HOT WELL OPERATION}

The steam after passing through low pressure turbine it goes to the condenser. In the condenser, the steam is turned in to water. Upon passing the turbine, the steam density, temperature and pressure get reduced. Hence, to suck the steam, a vacuum pressure is applied on steam by the condenser. Then the steam reaches the condenser and touches the water tubes which are carrying cool water from cooling towers and then the steam condensates in to the water and the water is collected at the bottom of the condenser. Here, the temperature of the water in the condenser will be approximately 30 to 40 degree Celsius. Hence, condenser is commonly called as HOT WELL [4].

The hot well level is to be maintained to normal level (200mm). This is why because, if the water level in the hot well goes below the desired level, the vacuum level increases so that the low pressure turbine blades gets sucked along with the steam by the vacuum pressure and if the water level in the condenser raises above the desired level, then deterioration of vacuum takes place. Hence, the water level in the hot well should be maintained to a fixed level [1]. Thus undesired water level in the hot well effects power plant efficiency. 


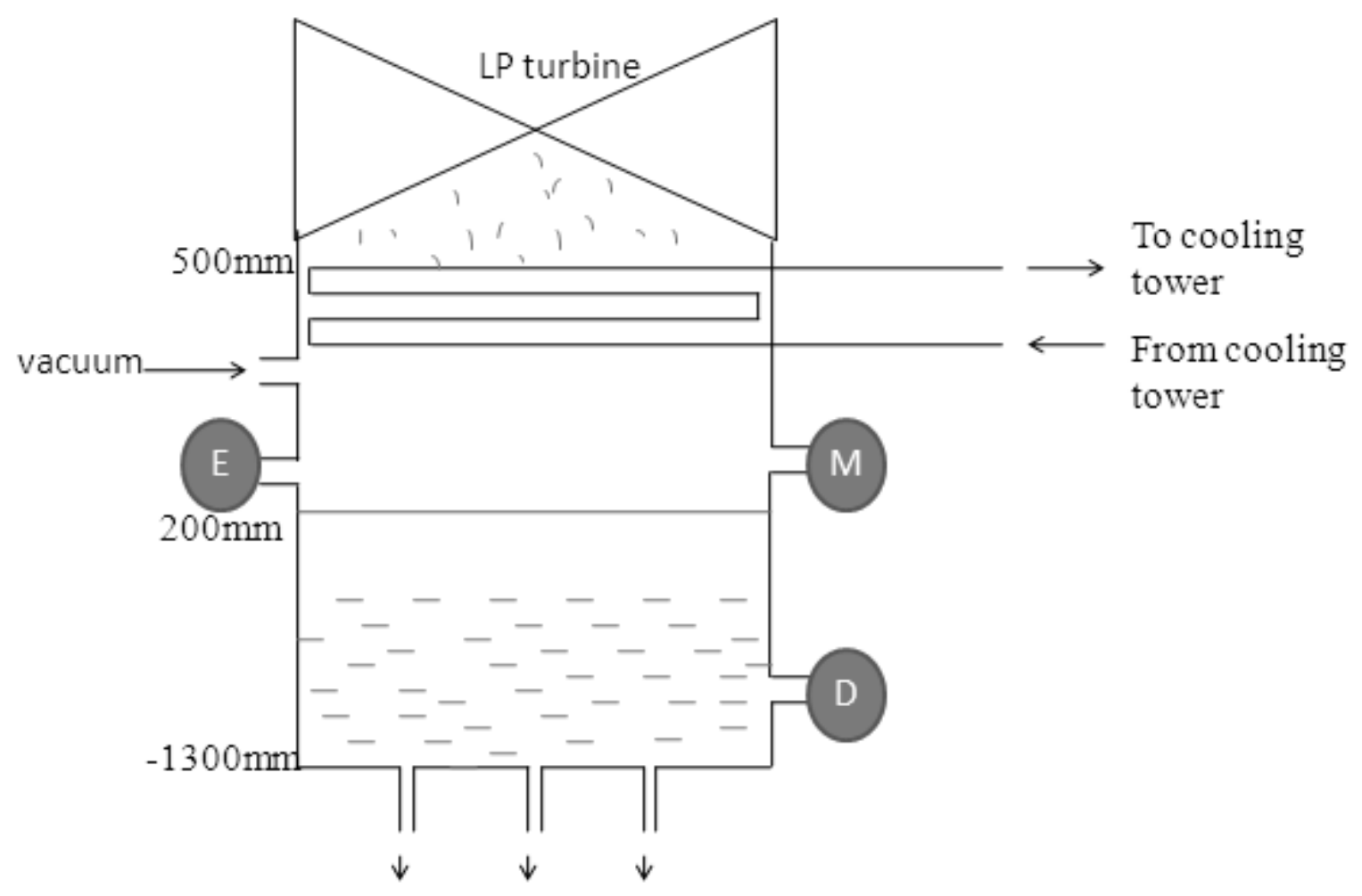

Fig 2. Hot well internal operation

When the water level is less than normal level say $199 \mathrm{~mm}$, then in order to make the water level to normal level, make up valve should be opened so that the water from demineralized water plant will flow in to the hot well and makes water level to normal. If the water level is much less than $199 \mathrm{~mm}$ i.e., when $190 \mathrm{~mm}$ then make up valve make use of emergency valve to make the hot well level to the normal level, that means these two valves get open at a time. And if the water level raises above normal level say $201 \mathrm{~mm}$ then excess water is to be moved out to the DM plant. This will be done by drain valve[7].

\section{EXISTING HOT WELL LEVEL CONTROL SYSTEM}

Right now in all thermal power plants the hot well level is measured by a level transmitter and it is compared to the set point. The error is given to PI controller whose output positions the control valve appropriately in order to maintain the hot well level [6].

The current signal in the range of $4-20 \mathrm{~mA} \mathrm{dc}$ is drawn by the level transmitter. The transmitter output current signal is connected to the another module which consist of $50 \mathrm{ohm}$ resistors and here voltage drop is trapped across the $50 \mathrm{ohm}$ resistors for measurement. This voltage is compared with the level set point and then the obtained error is given to the PI controller and Auto Manual Station. Here A/M station generates auto or manual signal to the PI controller so that PI controller performs its operations based on the signal received. The output of the controller is also in the range of $4-20 \mathrm{~mA}$. The $4-20 \mathrm{~mA}$ is first converted into 3-15 psi or $0.2-1 \mathrm{Kg} / \mathrm{sq} . \mathrm{cm}$. Pneumatic pressure signal by using Electric to Pneumatic converter (E/P).
This pneumatic signal is in sufficient for operating the final control valve.

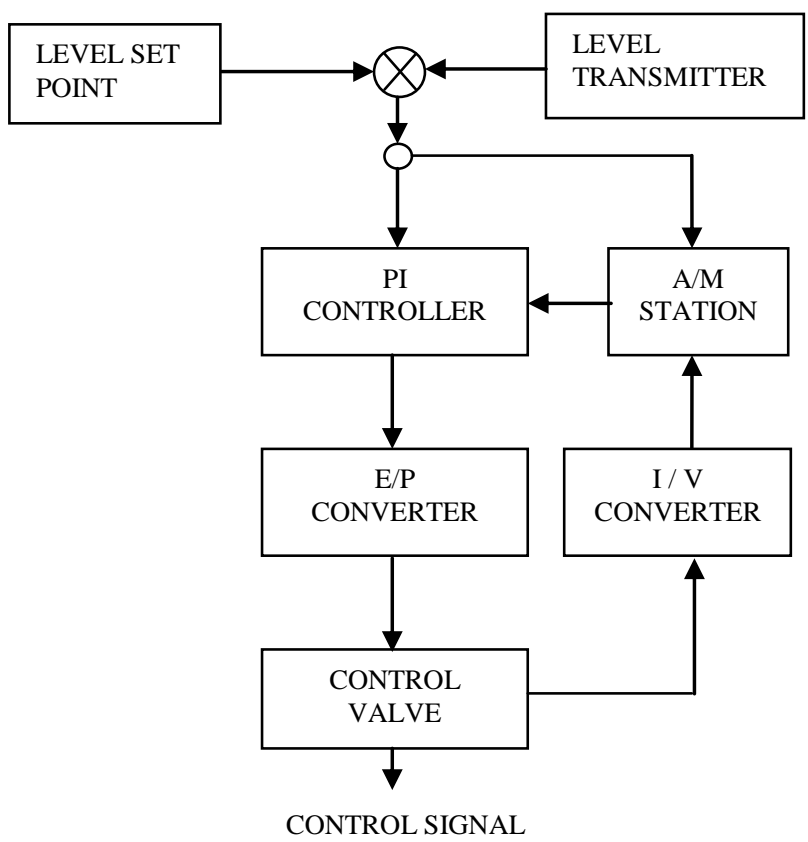

Fig 3. Existing hot well level control system

Here control valve generates the control signal which operates the corresponding valve. Then the valve position is converted into $4-20 \mathrm{~mA}$ current signal and in turn it is given to current to 
voltage converter .Here it gives corresponding voltage for given current. The obtained voltage is again given to $\mathrm{A} / \mathrm{M}$ station which in turn fed to PI controller. This process is repeated back by giving obtained error back to the PI controller.

\section{PROPOSED HOT WELL LEVEL CONTROL SYSTEM}

The proposed circuit is a simple, low cost, low power consumption, modified hot well level control system uses basic logic gates like AND, OR and NOT gates and ULN 2803 driver IC for controlling water pumps and led's to indicate corresponding levels of the water and buzzer to give siren when emergency pump gets on.

\subsection{Components used}

The components HCF4081B, CD4069 and HEF4071B operate over a recommended VDD power supply range of $3 \mathrm{~V}$ to $15 \mathrm{~V}$. Whereas for ULN 2803, it ranges from $0.5 \mathrm{~V}$ to $30 \mathrm{~V}$ [3] .Water pumps used here will operates for $+9 \mathrm{~V}$ supply. We can also use other pumps which operate for higher voltage but the power supply used for all the components in the circuit are should be same.

This IC consists of high voltage, high current Darlington transistor arrays suited to drive led's and water pumps. Mostly this IC is used in computer and industrial applications.

\subsubsection{HCF4081B}

This IC is called QUAD TWO INPUT AND GATE that provides four AND gates with direct implementation of the AND function. AND gate gives high voltage at output terminal when the high voltage is given to both the inputs or else for other inputs it gives low voltage output.

\subsubsection{CD4069}

This IC consists of six inverter circuits and is manufactured using CMOS with direct implementation of NOT function. NOT gate gives inverted output for corresponding input that means it gives high voltage as output for low voltage input and vice versa.

\subsubsection{HEF4071B}

This IC is a QUAD TWO INPUT OR GATE that provides four OR gates with direct implementation of the OR function. OR gate gives low voltage at output terminal when the low voltage is given to both the inputs or else for other inputs it gives high voltage output.

\subsubsection{ULN 2803}

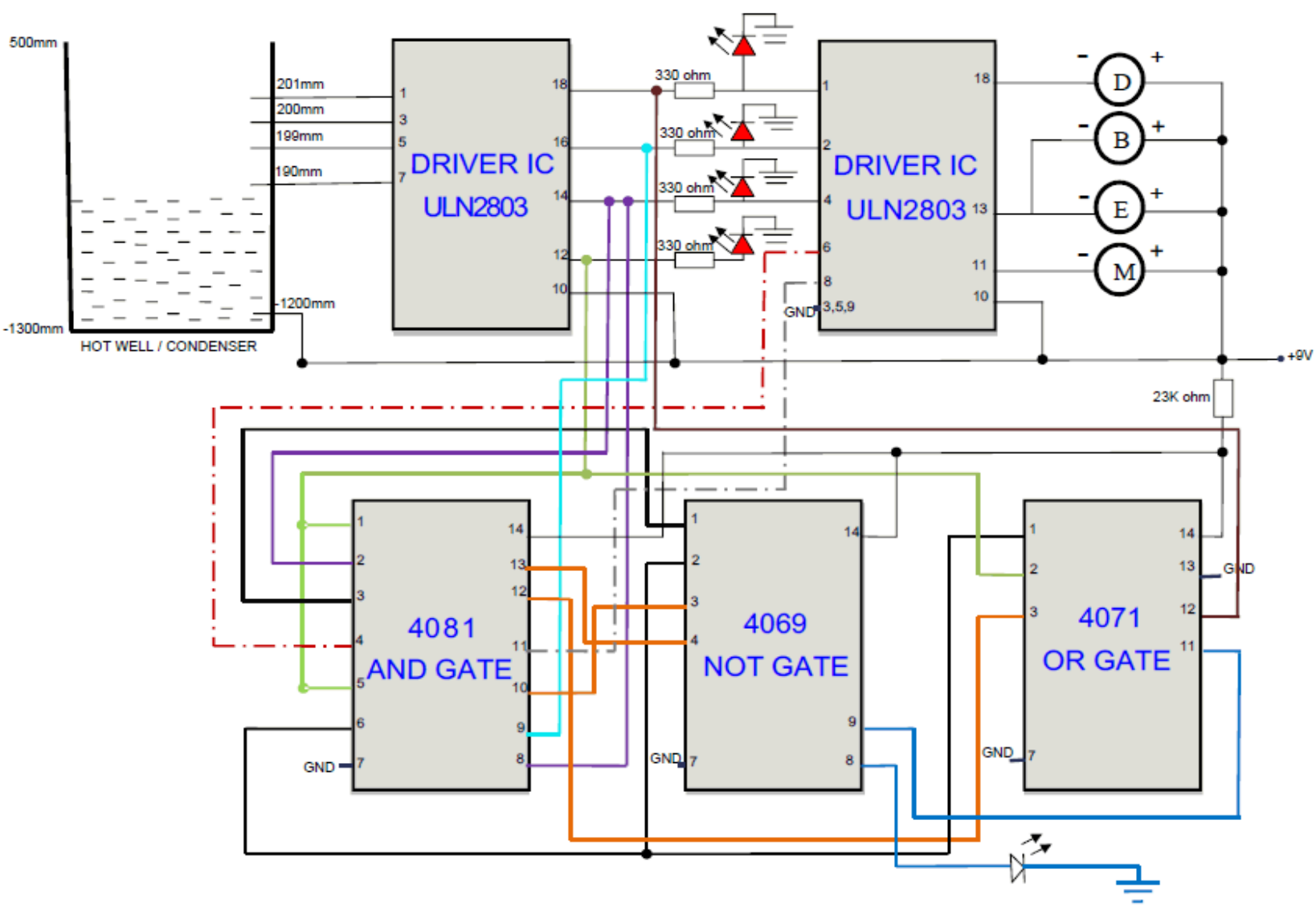

Fig 4. Proposed hot well level control system circuit diagram

\subsection{Circuit Description}

In the proposed circuit, the first driver IC i.e., ULN 2803 is used to drive the led's which indicates the level of the water in hot well. The second driver IC and logic gates are used to drive the water pumps and buzzer for corresponding levels. The reference wire is taken at $-1200 \mathrm{~mm}$ which is connected to $+9 \mathrm{~V}$ supply. And the four wires are taken at $201 \mathrm{~mm}, 200 \mathrm{~mm}, 199 \mathrm{~mm}$ and $190 \mathrm{~mm}$ levels which are connected to 1, 3, 5 and 7 pins of first ULN 2803 IC respectively. The four led's connected to the 18 , 16,14 and 12 pins of first driver IC. The corresponding led 
glows whenever water reaches that particular level. The led connected to $8^{\text {th }}$ pin of NOT gate glows when the water level reaches minimum required amount $200 \mathrm{~mm}$ and above. This indicates the safe mode.

\section{RESULTS AND DISCUSSIONS}

Assume that initially the water touches to $190 \mathrm{~mm}$ wire. Then the current travels from reference wire to $190 \mathrm{~mm}$ wire and hence the wire conducts the current. Then, the led connected to 12 th pin of first driver IC gets on and remaining led's are in off state. These results are given to the logic gates and in turn emergency, make up pumps and buzzer gets on. In order to understand the operation of the circuit in a simple way, let's consider the logic diagram of the circuit. It is clearly shown in Fig 5 the operation of each gate. In the similar way, for various levels different results will be observed as shown in Table 1 .

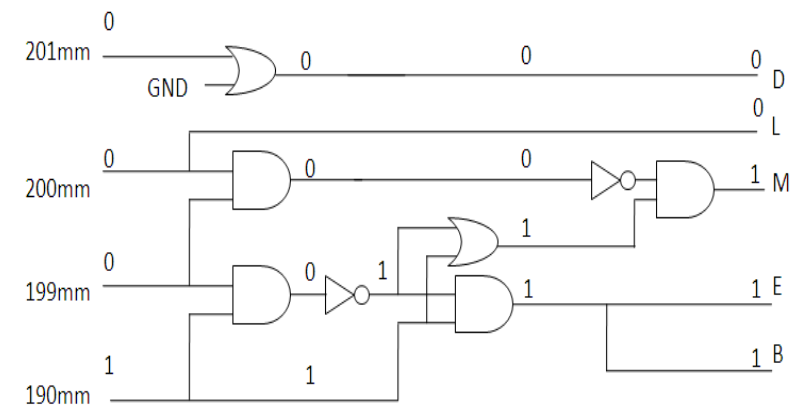

Fig 5. Logic diagram of the circuit

Here, logic 1 at corresponding level indicates that the water reaches that level and logic 0 indicates that water doesn't meet that level. GND in the sense indicates logic 0 .

Table 1. Switching operation for corresponding levels

\begin{tabular}{|c|c|c|c|c|c|}
\hline LEVEL & D & $\mathbf{L}$ & $\mathbf{M}$ & $\mathbf{E}$ & $\mathbf{B}$ \\
\hline $201 \mathrm{~mm}$ & ON & ON & OFF & OFF & OFF \\
\hline $200 \mathrm{~mm}$ & OFF & ON & OFF & OFF & OFF \\
\hline $199 \mathrm{~mm}$ & OFF & OFF & ON & OFF & OFF \\
\hline $190 \mathrm{~mm}$ & OFF & OFF & ON & ON & ON \\
\hline
\end{tabular}

In the table, the symbols D, L, M, E and B indicates Drain pump, Led, Makeup pump, Emergency pump and Buzzer respectively. It is practically observed that, when the water level is greater than normal level that means when it is $201 \mathrm{~mm}$, then drain pump gets on and special led also gets on indicating normal amount of water is available and when the level is equal to normal level that means when it is $200 \mathrm{~mm}$, then special led glows indicating the safe mode and when the level is less than normal level that means when it is $199 \mathrm{~mm}$, then makeup pump gets on and when the level is much less than normal level that means when it is less or equal to $190 \mathrm{~mm}$, then make up pump , emergency pump and buzzer gets on.

\section{COMPARISON BETWEEN EXISTING AND PROPOSED CONTROL SYSTEM}

- It is very complicated and costs more to design an existing hot well level control system where as it is simple and costs low to design proposed system.

- Proposed system consists of some extra features like indicating safe mode and giving siren when emergency pump gets on.

- Proposed system increases the temperature of the water for certain amount $2^{\circ} \mathrm{C}$ to $3^{\circ} \mathrm{C}$ whereas not possible by existing system.

- Proposed system can also used in real time applications like boiler drum control, reservoir water level control

\section{CONCLUSION}

The project "modified hot well level control system using basic logic gates" is proposed to control the level of water in the hot well. The system uses basic logic gates AND, OR and NOT gates and ULN 2803 IC to drive led's, buzzer and water pumps. This control system is also used to increase the water temperature at the range of $2^{\circ} \mathrm{C}$ to $3^{\circ} \mathrm{C}$. This project can be further applied for real time boiler, DM water plant level control applications as well.

\section{ACKNOWLEDGEMENT} Our special thanks to Sri VISHAL WANKHEDE, Asst. Mgr (C\&I), NTPC, RAMAGUNDAM and other colleagues for their insightful comments and constructive suggestions to improve the quality of this research.

\section{REFERENCES}

[1] POWER PLANT CONTROL AND INSTRUMENTATION, the control of boilers and HRSG systems by DAVID LINDSLEY, published by The Institution of Electrical Engineers, ISBN: 0-85296-765-9.

[2] Power Generation Handbook by PHILIP KIAMEH, McGraw- Hill Professional, and 1st edition (Aug 28 2002), ISBN: 0071396047.

[3] ELECTRONIC PROJECTS FOR BEGINNERS by A.K.MAINI, $5^{\text {th }}$ edition, 2001, ISBN: 81-223-0152-5.

[4] STEAM POWER PLANTS by IGOR J. KARASSIK AND RICHARD P. KOCH, section 9.5.

[5] Eun Gen Kim, 1990, Control System design of boiler level. In proceedings of ISL workshop, vol-3, February 7-9, 1990.

[6] SEIMENS manuals of stage-2 of National Thermal Power Corporation Limited Ramagundam.

[7] Schematic Diary of stage-2 of National Thermal Power Corporation Limited, Ramagundam. 